\title{
Proposta de Parâmetros para o Projeto de um Eletrodoméstico direcionado a pessoas com Deficiência Visual a partir dos Princípios do Design Universal
}

Proposal of Parameters for the Design of an Appliance for Persons with Visual Impairment, based on the principles of Universal Design

ANDRADE, Allisson; Graduando em Design; Universidade Federal da Paraíba

allisson502@gmail.com

DINIZ, Danielly; Graduanda em Design; Universidade Federal da Paraíba

dannydiniz14@gmail.com

IZAQUIEL, Irandir; Graduando em Design; Universidade Federal da Paraíba

irandirpitangadesigner@gmail.com

ACIOLY, Angélica; Doutora; DDesign, Universidade Federal da Paraíba

angelica@ccae.ufpb.br

ARAÚJO, Rodrigo; Doutorando em Design; Universidade Federal de Pernambuco

rodrigobarbosadesigner@gmail.com

\section{Resumo}

Uma boa interação entre produtos, usuários e ambientes proporciona a inclusão e facilita a vida de quem possui diferentes tipos de restrições. Com intuito de reduzir os riscos de acidentes em cozinhas domésticas, este artigo apresenta uma proposta de parâmetros de projeto de produto (fogão por indução) para pessoas com deficiência visual a partir dos princípios do Design Universal. Para tanto, este artigo apresenta seu embasamento teórico pautado no contexto de uso proposto, deficiência visual e no Design Universal. Apresenta ainda, testes preliminares de uso e análises do produto, usuário e contexto. Para o desenvolvimento do projeto foi aplicado um método com abordagem centrada no usuário - o Guia de Orientação para Desenvolvimento de Projetos (GODP). A coleta e organização dos dados possibilitou a geração de parâmetros relacionados à ergonomia, usabilidade e segurança, com o intuito de propiciar autonomia e independência ao usuário em potencial.

Palavras Chave: Deficiência Visual; Inclusão; Eletrodoméstico.

\section{Abstract}

A good interaction between products, users and environments provides the inclusion and facilitates the life of those who have different types of restrictions. In order to reduce the risk of accidents in domestic kitchens, this article presents a proposal for product design parameters (induction cooker) for people with visual impairment from the principles of Universal Design. For this, this article presents its theoretical basis based on the context of proposed use, visual impairment and in Universal Design. It also presents preliminary tests of use and analysis of the product, user and context. A method with a user-centered approach - the Guidance for Project Development (GODP) - 
was applied to the project development. The collection and organization of data enabled the generation of parameters related to ergonomics, usability and safety, in order to provide autonomy and independence to the potential user.

Keywords: Visual Impairment; Inclusion; Household Appliance.

\section{Introdução}

O não atendimento às necessidades de pessoas com alguma deficiência visual ainda é bastante recorrente nos dias atuais. O desenvolvimento de produtos e a tecnologia, muitas vezes, deixam de atender este público, e o que era para ser um direito de todos, acaba se tornando apenas de alguns. Ao invés de benefícios, há uma percepção de que cada vez mais são construídas barreiras, limites e restrições para essa minoria.

Neste sentido, este artigo apresenta um tema de grande relevância social e contribuições do design para a inclusão social de pessoas com deficiência visual, usuárias de eletrodomésticos, levando em consideração suas capacidades e limitações. No contexto da cozinha, a organização, os alcances e a limpeza, são fatores que contribuem para um bom desempenho na utilização do ambiente. Relacionando tais aspectos aos deficientes visuais, por vezes são necessárias adaptações que visam promover o acesso e a mobilidade adequada a este púbico.

A relevância de se projetar um fogão para usuários com deficiência visual, surgiu de uma necessidade básica da vida cotidiana dos seres humanos, que é a prática de cozinhar. Embora haja o preconceito e a não aceitação ou rejeição para o fato de um deficiente visual realizar atividades culinárias, visto que, as pessoas normovisuais por serem tão dependentes da visão, muitas vezes não percebem que por meio de outros sentidos também é possível realizar tarefas triviais na cozinha, como por exemplo identificar quando o alimento está pronto. Neste contexto, assim como em outros, a visão atua em conjunto aos demais sentidos.

lida (2005) apresenta como uma proposta de adequação de um produto a públicos considerados minoritários - o projeto "universal", onde o mesmo se preocupa em dotar o produto ou ambiente com as características que facilitem o seu uso pela maioria das pessoas, incluindo algumas minorias, como os canhotos, idosos e portadores de deficiências físicas.

Sendo assim, este artigo tem como objetivo, apresentar uma proposta de parâmetros de projeto de produto (fogões por indução) para pessoas com deficiência visual a partir dos princípios do Design Universal. Esta proposta surgiu como atividade projetual em uma disciplina do Curso de Design da UFPB, cuja demanda foi identificada a partir de questionamentos sobre possíveis dificuldades sentidas por deficientes visuais e riscos eminentes deste tipo de produto, além da coleta de dados por meio de relatos deste público, surgindo assim a problematização do projeto.

\section{Embasamento Teórico}

\subsection{Design Universal (DU) - Definições e Princípios}

Segundo o Centro de Design Universal (CUD) da Universidade de Carolina do Norte (EUA) o DU trata de princípios aplicados a produtos e a ambientes para serem usados por todas as pessoas, na maior extensão possível, sem a necessidade de adaptação ou design especializado.

Duncan (2013) aponta que o termo Design Universal foi inicialmente usado em meados da década de 1980 nos Estados Unidos (EUA), pelo arquiteto Ronald L. Mace, desde então tem se 
espalhado pelo mundo e agregando alguns conceitos relacionados como o "Design para Todos", "Projeto Esperança de Vida", e "Design Inclusivo". Esforços de acessibilidade e os valores fundamentais do movimento pelos direitos dos deficientes em grande parte formou a base sobre a qual os conceitos universais de projeto foram construídos. O DU e a acessibilidade, portanto, possuem bastante semelhança na sua base filosófica: a inclusão, a participação plena e igualdade social. Ainda segundo o autor, o DU pode repercutir em outras áreas ou movimentos que, num primeiro momento, não teria uma ligação direta, como por exemplo a sustentabilidade:

O DU, como parte de um ambiente de apoio e capacitação, pode ser visto como um componente da sustentabilidade social, pois ajuda a plena inclusão e participação na vida familiar e comunitária para todos. Habitação universal também conecta bem com o movimento de sustentabilidade ambiental (DUNCAN, 2013).

Quando os conceitos de DU se referem a "todas as pessoas", o alcance a "todas" significa que um projeto deveria ser acessível a todas as pessoas de todos os aspectos. Sabe-se, contudo, que devido a uma grande diversidade de populações e dados antropométricos, de questões envolvidas na relação usuário/produto, de ordem física, cognitiva, social, cultural, entre outros; esse objetivo torna-se inviável de ser alcançado na sua totalidade. Todavia, seus princípios trabalham como meta, buscando assim alcançar o máximo possível de usuários.

Para tanto, o Centro de Design Universal da Universidade de Carolina do Norte apresenta os seguintes princípios de projeto:

1- Uso Equitativo: O design é útil e vendável para pessoas com habilidades diversas. 1 a. Oferece o mesmo modo de uso para todos os usuários. 1 b. Evita segregar ou estigmatizar qualquer usuário. 1 c. Disposições de privacidade e segurança devem estar igualmente disponíveis para todos os usuários. $1 \mathrm{~d}$. Torna o design atraente para todos os usuários.

2 - Flexibilidade no Uso: O design acomoda uma ampla gama de preferências e habilidades individuais. 2 a. Oferece escolha quanto ao método de utilização. 2 b. Acomoda acesso e utilização tanto para destros quanto canhotos. 2 c. Facilita ao usuário o uso com exatidão e precisão. 2 d. Oferece adaptabilidade ao ritmo do usuário.

3 - Uso Simples e Intuitivo: O uso do design é fácil de entender, independentemente da experiência, conhecimento, habilidades de linguagem ou nível de educação do usuário. 3 a. Elimina complexidade desnecessária. 3 b. É consistente com as expectativas e intuição do usuário. 3 c. Acomoda uma ampla gama de habilidades de linguagem e grau de instrução. 3


feedback durante e após conclusão da tarefa.

4 - Informação Perceptível: O design comunica informação necessária ao usuário de maneira efetiva, independentemente das condições do ambiente ou das habilidades sensoriais do usuário. 4 a. Utiliza diferentes modos (pictórico, verbal, táctil) para apresentação redundante de informações essenciais. 4 b. Fornece contraste adequado entre informação essencial e suas imediações. 4 c. Maximiza a legibilidade de informação essencial. $4 \mathrm{~d}$. Diferencia elementos de modo que possam ser descritos (torna fácil dar instruções ou orientações). 4 e. Fornece compatibilidade com uma variedade de técnicas ou dispositivos utilizados por pessoas com limitações sensoriais.

5 - Tolerância ao Erro: $O$ design minimiza acidentes e as consequências adversas de atitudes acidentais ou não intencionais. 5 a. Organiza elementos que minimizam acidentes e erros; elementos mais utilizados são os mais acessíveis; elementos passíveis de provocar acidentes são eliminados, isolados ou protegidos. 5 b. Fornece advertências com relação a acidentes e erros. 5 c. Fornece características de segurança quanto às falhas. $5 \mathrm{~d}$. Desencorajam atitude inconsciente em tarefas que requeiram estado de vigilância. 
6 - Pouco Esforço Físico: O design pode ser usado de forma eficiente e confortável e com um mínimo de fadiga. 6 a. Permite ao usuário manter um posicionamento corporal neutro. 6 b. Utiliza força razoável para operar. 6 c. Minimiza ações repetitivas. 6 d. Minimiza o uso de esforço prolongado.

7 - Tamanho e Espaço para Abordagem e Uso: Tamanho apropriado e espaço é fornecido para a abordagem, alcance, manipulação e uso, independentemente do tamanho do corpo do usuário, postura e mobilidade. 7 a. Oferece uma linha clara de visão de elementos importantes para usuários sentados ou em pé. 7 b. Torna confortável alcançar todos os componentes, para usuários sentados ou em pé. 7 c. Acomoda variações quanto ao tamanho da mão ou da pegada. $7 \mathrm{~d}$. Fornece espaço adequado para o uso de equipamento de assistência ou assistência pessoal (CUD, 2014, apud MERINO, 2014, p. 60-63).

Estes princípios reforçam mais uma vez, formas pelas quais é possível facilitar as atividades diárias de uma diversidade de pessoas. Diretrizes que, de forma abrangente, podem atingir não somente pessoas que apresentam restrições/limitações, mas também ao público em geral que não necessita de cuidados específicos.

\subsection{Deficiência Visual}

Segundo Rocha (2009), a maioria das informações recebidas pelo cérebro nos chega por meio dos olhos. A visão é o sentido que domina a nossa vida, sendo este o mais significativo, é o sentido que nos aproxima ao mundo objetivo, e desempenha um papel imprescindível por representar a maior parte de sensações e emoções que temos do mundo. Sendo assim, o cuidado com os olhos é muito importante para a saúde em geral, sendo a visão um essencial meio de relação do indivíduo com o mundo exterior, onde há uma interação do ser humano com o contexto em que observa, sendo sua assimilação obtida em maior ou menor grau por meio dos olhos (GOUVÊA LÁZARO, MAIA, 2009).

A deficiência visual é uma realidade cada vez mais frequente em nosso meio. De acordo com dados obtidos pela Organização Mundial da Saúde, estima-se que no Brasil existem mais de 750 mil pessoas com deficiência visual, e esse número cresce cada vez mais (VENTAVOLI, 2012). A respeito da classificação dessa deficiência, existem diferentes graus, onde de um grupo para outro existe uma variação de perdas que se caracteriza por diferentes graus de acuidade visual. Esta variação pode representar uma perda desde a percepção de luz até o limiar da normalidade (MIRANDA, 2001). São eles:

Cegueira (ausência total de visão e luminosidade): definida como falta do sentido da visão, podendo ser total ou parcial. [...] Visão Parcial: têm limitações da visão à distância, mas são capazes de ver objetos e materiais quando estão a poucos centímetros ou no máximo a meio metro de distância. Baixa Visão ou Visão Subnormal: aquele que apresenta a capacidade de perceber luz, até o grau em que a deficiência visual limita seu desempenho, que podem ter seu problema corrigido por cirurgias ou pela utilização de lentes. (VENTAVOLI, 2012, p. 36-38).

Dentre as principais causas da deficiência visual, têm-se as seguintes (SANTOS et al, 2012):

- Congênitas: amaurose congênita de Leber, malformações oculares, glaucoma congênito, catarata congênita; e

- Adquiridas: traumas oculares, catarata, degeneração senil de mácula, glaucoma, alterações relacionadas à hipertensão arterial ou diabetes.

A deficiência visual caracteriza-se pela limitação ou perda das funções básicas do olho e do sistema visual, porém muitas pessoas confundem e acham que os deficientes visuais possuem 
inúmeras limitações, portanto, não podem desenvolver as atividades que costumeiramente as pessoas sem deficiências desenvolvem. Ventavoli (2012, p. 10) acredita que existem maneiras de mudar esse cenário, quando coloca que com tratamento, atendimento educacional adequado, programas e serviços especializados ao deficiente, este tipo de restrição não ameaçará a vida plena e produtiva do indivíduo.

\subsection{Ambiente da Cozinha - Riscos de Acidentes}

Atualmente as pessoas costumam permanecer muito mais tempo na cozinha do que em outros ambientes da casa, e isso faz com que elas busquem cada vez mais organização, limpeza e sofisticação, tanto para o ambiente, como por meio do uso de utilitários. Mas por trás desse hábito, existem alguns problemas ocultos, como a falta de acessibilidade e segurança a todos, e principalmente para pessoas com deficiência, que enfrentam limitações com relação à locomoção ou durante o manuseio e utilização de utensílios domésticos.

Em termos gerais, a cozinha é por definição, um ambiente que apresenta alguns riscos iminentes aos seus usuários. Riscos como cortes, queimaduras, quedas, dentre outros. Segundo uma pesquisa apresentada pela Revista Brasileira de Saúde Ocupacional no ano de 2015, cerca de $8 \%$ dos pacientes atendidos em centros de queimaduras são trabalhadores de cozinhas (FOOD SERVICE NEWS, 2015). Os riscos na cozinha são constantes, mesmo para pessoas que não possuem algum tipo de deficiência.

Todos os anos são registrados inúmeros acidentes relacionados ao uso de eletrodomésticos no contexto da cozinha. De acordo com a pesquisa realizada pelo Inmetro durante 2016, os produtos que mais causam acidentes de consumo foram fogões (10\%), seguido por outros produtos, como eletrodoméstico portátil de cozinha $(4,5 \%)$, panelas $(4,1 \%)$, dentre outros. Segundo os relatos pelo SINMAC as lesões mais comuns são cortes, queimaduras, escoriações/arranhões. Segundo o levantamento as partes do corpo mais afetadas são os dedos das mãos, com $12 \%$ dos relatos, e mãos, com 7\% (INMETRO, 2016).

\section{Procedimentos Metodológicos}

Para o desenvolvimento do projeto, foi necessário realizar em uma primeira etapa, a definição da problemática e a aproximação com o tema por meio de uma pesquisa bibliográfica, onde foram pesquisadas algumas referencias em livros, artigos científicos e portais especializados.

A segunda etapa do trabalho refere-se à condução das fases do desenvolvimento do projeto, apresentando parâmetros direcionados ao desenvolvimento de fogões para deficientes visuais. Consistindo assim, na aplicação dos conhecimentos teóricos na prática projetual.

O método projetual adotado foi o GODP (Guia de Orientação para Desenvolvimento de Projetos), desenvolvido por Merino (2016). Trata-se de um método centrado no usuário, ou seja, ele trata das capacidades humanas: sensorial, que envolve os sentidos (visão, audição, olfato e paladar); cognitiva, que envolve o pensamento e comunicação; e motora, que envolve questões como o alcance, locomoção e a destreza. Essas capacidades estão juntamente associadas com as dimensões temporal (nascer, crescer e envelhecer) e social (aspectos culturais e de contexto), configurando assim um processo que é altamente empático. O método está dividido em três grandes momentos: Inspiração, Ideação e Implementação (MERINO, 2016). 
O presente artigo, não traz todas as etapas do método citado, já que a função principal do mesmo é relatar o processo de projetação até o momento da análise e organização dos dados coletados, apresentados em forma de parâmetros, que aqui estão representados até a Etapa (2) do método. Os momentos e etapas apresentados são os seguintes:

- Momento Inspiração: Etapa (-1) Oportunidades - verificação das oportunidades de mercado conforme o produto avaliado através de pesquisa bibliográfica e de mercado; Etapa (0) Prospecção/Solicitação - definição da demanda e problemática central do projeto; Etapa (1) Levantamento de Dados - que tem como base as necessidades do usuário, e envolveu testes de usabilidade e análise ergonômica com um modelo de fogão por indução disponível no mercado, a partir dos princípios do Design Universal; e

- Momento Ideação: Etapa (2) Organização e Análise de Dados - onde foi organizado o levantamento de informações em forma de dados e análise dos mesmos, e elaboração dos requisitos e parâmetros de projeto para um novo produto.

A amostra de usuários para os testes de simulação de uso foi definida de forma aleatória e composta por 5 (cinco) estudantes universitários videntes, os quais foram vendados para os testes de simulação. Não houve a possibilidade da realização dos testes com deficientes visuais, pois não havia no Campus da universidade no período do projeto, estudantes com deficiência visual disponíveis para a realização dos mesmos.

Foram realizados testes preliminares de simulação de uso com a amostra selecionada com a aplicação de questionários. O questionário utilizado tratou, em termos gerais, do perfil dos usuários e as experiências anteriores com fogões e similares, além do registro dos testes de uso. $\mathrm{O}$ teste com o produto similar coletou informações sobre experiências durante o uso, pontos positivos e negativos identificados pelos participantes, e sugestões de melhorias. Os responsáveis pela coleta dos dados foram os próprios desenvolvedores do projeto.

Quanto aos princípios do Design Universal, o método utilizado propõe uma análise por meio de um Checklist composto pela verificação de sete princípios propostos pelo Centro de Design Universal da Universidade de Carolina do Norte (CUD), quais sejam: Uso equitativo, Flexibilidade no uso, Uso Simples e Intuitivo, Informação Perceptível, Tolerância ao Erro, Pouco Esforço Físico, Tamanho e Espaço para Abordagem e Uso); os quais consideram que um projeto que seja acessível à todos, será aquele em que se prevê o uso do produto em diferentes situações, as diversas funcionalidades que podem ser atribuídas e a prática do usuário, não importando a idade.

\section{Desenvolvimento}

\section{1 Momento 1: Inspiração}

No primeiro momento do método, as etapas citadas a seguir, consistem em uma préprojetação, onde são realizadas pesquisas, levantamento de dados e estudos que darão um melhor direcionamento para o projeto.

$\mathrm{Na}$ etapa -1 (Oportunidades) foram realizadas pesquisas bibliográficas relacionadas a eletrodomésticos de cozinha, visando uma melhor compreensão, clareza e objetividade, onde se fez necessário um aprofundamento sobre acidentes ocorridos com usuários, causados por eletrodomésticos. Na busca por projetar um produto mais satisfatório aos usuários, coletou-se reclamações frequentes feitas pelos mesmos, em relação ao uso dos eletrodomésticos em sites 
técnicos, a exemplo do INMETRO/SINMAC, dentre outros.

Para o andamento e continuidade do projeto, norteou-se o produto e o público alvo a serem trabalhados, os quais foram determinados pela equipe como: um fogão direcionado principalmente aos deficientes visuais, mas que também agregasse o público em geral, ou seja, aqueles que não precisam de produtos adaptados. Daí então, foram geradas a identificação de demandas e possibilidades.

Na Etapa 0 (Prospecção/solicitação) foi realizada uma busca em lojas físicas e virtuais por produtos similares ao que seria projetado. De acordo com o levantamento preliminar de mercado, os sites em que mais foram encontrados produtos do tipo "fogão por indução", foram duas marcas nacionais. Foram encontrados produtos que apresentam uma variação de preço entre $R \$ 204,99$ a $\mathrm{R} \$ 3.120,00$. Em seguida, foram pesquisados alguns pontos de vendas do produto. Os principais fornecedores desse tipo de produto são lojas físicas e sites e-commerce. Ficou constatado que a maioria dos produtos que são ofertados nas lojas físicas também são encontrados nos sites.

Em relação às pesquisas de viabilidade legal, foi feita uma busca de patentes relacionadas ao tema no site do INPI - Instituto Nacional de Propriedade Industrial. Não foram encontrados registros que se referem a "fogão elétrico portátil por indução". Houve resultados apenas para "fogão elétrico" e "fogão a gás". Bem como não foram encontrados registros que se referem a "fogão universal por indução para pessoas com deficiência visual". Há registros de fogões de vários tipos, porém, com a especificidade do projeto vigente não foram encontrados.

Durante as pesquisas realizadas com relação aos produtos similares existentes no mercado, foi observado que existem poucos fogões diretamente direcionados a deficientes visuais, e os existentes não atendem às necessidades principais. Foram constatados relatos de alguns deficientes visuais, onde na maioria deles ficou notório que uma das maiores dificuldades encontradas no uso dos fogões convencionais, é o mal posicionamento das panelas, dado pelo fato dos usuários não conseguirem centralizá-las corretamente nas bocas dos fogões.

Após as observações e análises de oportunidades de mercado, foram definidas as demandas, a problemática principal, e o perfil dos usuários, respectivamente. Os usuários, portanto, seriam adultos de 20 a 60 anos de classe média/alta. A classe foi definida com base nos preços da faixa de consumo de fogões do tipo indução. A problemática definida foi a dificuldade de uso do fogão por uma pessoa com deficiência visual, além da oportunidade da escassez de produtos existentes no mercado direcionados a esse público.

Na Etapa 1 (Levantamento de dados), foram pesquisados produtos disponíveis no mercado similares à proposta do projeto. Ou seja, modelos de cooktops portáteis e preços de fogões que utilizam a tecnologia da indução, destinados ao público em geral. Foram selecionados seis modelos (Figura 1). Em termos gerais, foi constatado que os fogões portáteis geralmente possuem apenas uma boca, e custam entre $R \$ 299,00$ a $R \$ 488,04$. Os de cozinha, que possuem mais bocas tem um custo mais elevado, chegando a $\mathrm{R} \$ 2.969,10$. 
Figura 1 - Modelos selecionados
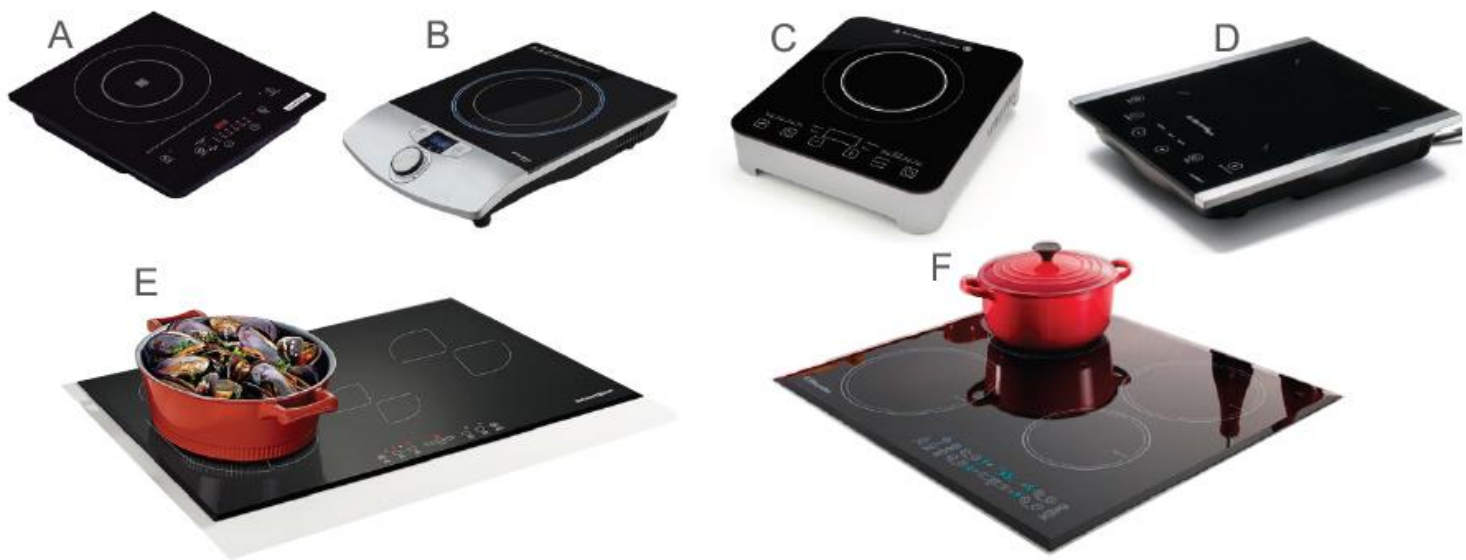

Fontes: A - Buscapé.com (2017); B - Cadence.com (2017); C - Polishop.com (2017); D - 4 Buscapé.com (2017); E - Buscapé.com (2017); F - Wallmart (2017).

Em seguida, pelo critério de acesso ao produto, foi selecionado o modelo ' $D$ ' (Figura 1) para simulação de uso e realização dos testes com usuários com o intuito de fazer um levantamento de dados. O modelo ' $D$ ' apresenta as seguintes características: elétrico com funcionamento por indução; possui uma boca; composto por polímeros, metais e uma superfície vitrocerâmica; predominância da cor preta; possui um painel digital com funções de uso através de botões sensiveis ao toque (touchscreen), possui a função travar, que impede o acionamento de botões por acidente; potência de aquecimento que vai de 1 a 6; função timer e peso aproximado de 2 (dois) quilogramas.

Logo após, foi realizada uma análise da tarefa de uso do fogão por indução. As tarefas prescritas foram registradas em um quadro, com o objetivo de descrever os passos para o acionamento do fogão avaliado (Quadro 1).

Quadro 1: Descrição das tarefas

\begin{tabular}{|c|c|c|c|c|}
\hline Tarefa & Descrição & Desenho/Foto & Ação & $\begin{array}{l}\text { Tipo de } \\
\text { pega }\end{array}$ \\
\hline 1. Tarefa & $\begin{array}{l}\text { Ligar/desligar } \quad \text { o } \\
\text { fogão }\end{array}$ & & Com uma das mãos, pegar & Pega de \\
\hline $\begin{array}{l}\text { Sub-tarefa } \\
1.1\end{array}$ & $\begin{array}{l}\text { Conectar o plugue à } \\
\text { rede elétrica }\end{array}$ & & $\begin{array}{l}\text { o plugue e coloca-lo na } \\
\text { tomada; }\end{array}$ & $\begin{array}{l}\text { precisao e } \\
\text { manejo fino }\end{array}$ \\
\hline $\begin{array}{l}\text { Sub-tarefa } \\
1.2\end{array}$ & $\begin{array}{l}\text { Colocar a panela } \\
\text { sobre o fogão }\end{array}$ & & $\begin{array}{l}\text { Com uma das mãos, pegar } \\
\text { a panela pelo cabo e } \\
\text { colocá-la na parte } \\
\text { sinalizada, ao centro do } \\
\text { fogão; }\end{array}$ & $\begin{array}{l}\text { Pega de } \\
\text { empunha- } \\
\text { dura e } \\
\text { Manejo } \\
\text { grosseiro }\end{array}$ \\
\hline
\end{tabular}




\begin{tabular}{|c|c|c|c|}
\hline $\begin{array}{l}\text { Sub-tarefa } \\
1.3\end{array}$ & $\begin{array}{l}\text { Pressionar o botão } \\
\text { de ligar/desligar, } \\
\text { para ligar o fogão. }\end{array}$ & $\begin{array}{l}\text { Com uma das mãos, } \\
\text { pressionar levemente o } \\
\text { botão de ligar/desligar; }\end{array}$ & $\begin{array}{l}\text { Pega de } \\
\text { precisão e } \\
\text { manejo fino }\end{array}$ \\
\hline $\begin{array}{l}\text { Sub-tarefa } \\
1.4\end{array}$ & $\begin{array}{l}\text { Ajustar a potência } \\
\text { para manter o fogão } \\
\text { ligado. }\end{array}$ & $\begin{array}{l}\text { Com uma das mãos, } \\
\text { pressionar o botão "_" ou } \\
\text { "+" para aumentar ou } \\
\text { diminuir a potência; }\end{array}$ & $\begin{array}{l}\text { Pega de } \\
\text { contato e } \\
\text { manejo fino }\end{array}$ \\
\hline $\begin{array}{l}\text { Sub-tarefa } \\
1.5\end{array}$ & $\begin{array}{l}\text { Pressionar o botão } \\
\text { de ligar/desligar, } \\
\text { para desligar o } \\
\text { fogão. }\end{array}$ & $\begin{array}{l}\text { Com uma das mãos, } \\
\text { pressionar levemente o } \\
\text { botão de ligar/desligar. }\end{array}$ & $\begin{array}{l}\text { Pega de } \\
\text { precisão e } \\
\text { manejo fino }\end{array}$ \\
\hline
\end{tabular}

Fonte: Os autores (2017).

Pelo fato do projeto estar direcionado aos deficientes visuais, e por não ser possível à época realizar testes de uso do produto com este público, como já mencionado, foi decidido que havia a necessidade do ser realizado com participantes vedados, o que limitaria visualmente o usuário ao manusear o produto, simulando uma situação de cegueira real.

Os usuários participaram da pesquisa de forma voluntária, mediante assinatura do Termo de Consentimento Livre Esclarecido (TCLE). Após o teste foram aplicados dois questionários, que se tratavam da experiência que eles tiveram com a utilização do fogão por indução portátil. A amostra de usuários para o teste de usabilidade foi composta por 05 (cinco) estudantes universitários, com idades entre dezenove e vinte e dois anos: 01 (um) usuário com 19 anos; 01 (um) usuário com 20 anos; 01 (um) usuário com 22 anos; 02 (dois) usuários com 21 anos. Sendo a maioria (60\%) do sexo feminino e $40 \%$ do sexo masculino. Todos os voluntários nunca haviam participado ou respondido testes e questionários de usabilidade antes.

Sobre a experiência prévia com esse tipo de produto, os participantes afirmaram que possuem hábitos de cozinhar, e utilizam fogões em média duas vezes ao dia, com duração de 3 minutos a 40 minutos. 04 (quatro) usuários disseram que utilizam o fogão diariamente, e apenas 01 (um) que usa às vezes. Todos os participantes afirmaram que utilizam o fogão tradicional a gás.

No teste de uso, os usuários foram vendados e tiveram um primeiro contato com o produto sem saber ainda do que ele se tratava. Posicionados em frente ao fogão, foi solicitado que eles o tocassem e identificassem de qual produto se tratava.

Durante os testes com os usuários vendados foi necessário manter os devidos cuidados e orientações de segurança com o uso do produto. A equipe acompanhou e guiou todo o processo e foram dadas as instruções para realização de cada etapa do teste. Foi importante alertar os usuários que a superfície do fogão aquece durante o uso, o conteúdo da panela foi reduzido e eram dados alertas de precaução constantemente, a fim de que, fosse resguardada a integridade física dos participantes. Vale ressaltar que o modelo de fogão utilizado apresenta cinco níveis de aquecimento e que os testes estavam sendo realizados no nível mais baixo da temperatura para que não ocorresse a possibilidade de queimaduras. 
Nenhum dos usuários participantes da pesquisa conseguiu identificar inicialmente de que se tratava de um fogão, assim como não conseguiram efetuar com facilidade as funções básicas do produto, como ligar/desligar. Após um breve esclarecimento de qual produto se tratava, todos conseguiram ligar o fogão, levando para realizar a função ligar/desligar, de 10 a 40 segundos.

Figura 2: Teste de uso com usuários vendados.

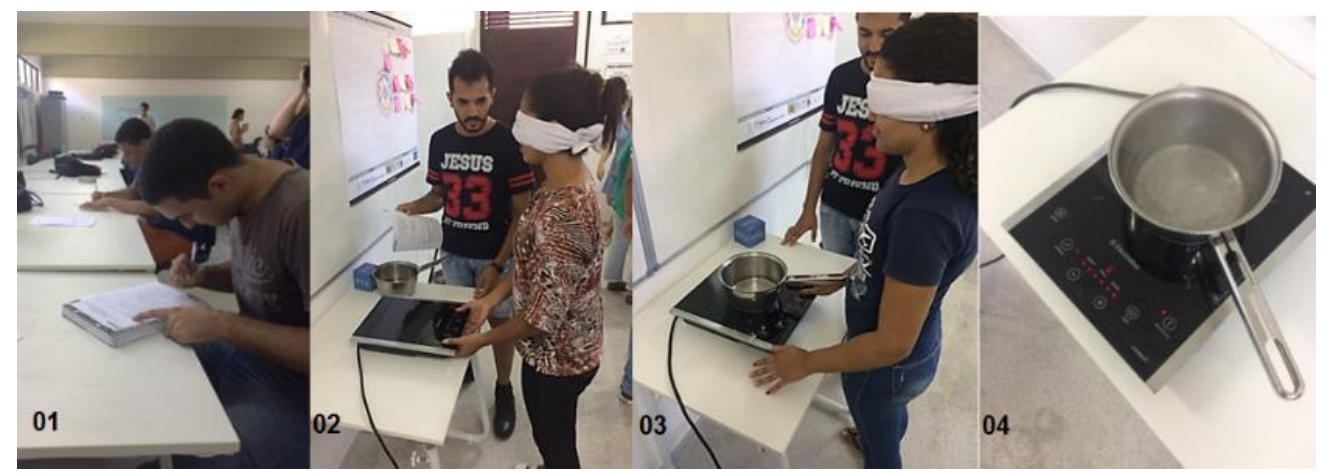

Fonte: Os autores (2017).

No contato inicial com o produto, os usuários chegaram a confundir o fogão com uma balança eletrônica, mesmo após visualizarem o produto, onde relataram que isso se deu devido à forma e à configuração estética do produto, que não apresentava nenhum tipo de identificação que possibilitasse a fácil compreensão do mesmo. Sua forma não atendia ao estereótipo dos usuários, pois fugia do que era convencional para este tipo de produto. O fogão não apresenta relevo, textura ou algo semelhante que ajudasse a entender às funções principais, como ligar/desligar e ajustar a potência.

Quatro usuários levaram em torno de 40 segundos para a identificação e uso do produto. Pôde-se considerar então que, levaram um tempo relativamente alto, para realizar uma tarefa que é relativamente simples. No primeiro momento dos testes, ficou claro então que houve uma má leitura e percepção do produto.

Em relação ao uso de fogões em geral, quando perguntados, um dos participantes afirmou que encontrou dificuldades em relação à temperatura das panelas, dois usuários disseram que tiveram dificuldades na hora de ligar, e os outros dois disseram não possuir nenhuma dificuldade. Todos os usuários afirmaram que se sentem seguros ao utilizar um fogão sozinho e que nunca sofreram acidentes durante o uso do fogão.

Quanto aos princípios do Design Universal, após a aplicação do Checklist previsto no método, foi constatado que o produto avaliado, o fogão por indução portátil modelo ' $D$ ', atendeu à maioria dos princípios, onde 6 (seis), de 7 (sete) princípios, foram atendidos, e receberam a avaliação "concordo". Contudo, o princípio 3 (três) não recebeu uma boa avaliação, teve em sua maioria a opção "discordo". Esse princípio refere-se ao "uso simples e intuitivo", o que seria o uso do produto por diferentes tipos de usuários em potencial.

\section{2 Momento 2: Ideação}

Este momento teve como objetivo, analisar os dados coletados e estabelecer os parâmetros de projeto para o novo produto. 
Na Etapa 2 (Análise de dados) foram conduzidas algumas análises (sincrônica, diacrônica, ergonômica, público alvo e do contexto, com base em autores do design) e a organização dos dados gerados, para que assim fossem definidas as estratégias de projeto. Neste trabalho será apresentada a síntese apenas das análises ergonômica e do público alvo, realizada de acordo com critérios propostos por Gomes Filho (2009) e lida (2015).

A análise Ergonômica apresentada brevemente a seguir, foi realizada com o mesmo produto que foram realizados os testes de uso. A análise apresentou os seguintes dados:

- Segurança: o fogão apresenta aparente segurança. Devido ao seu funcionamento ser por indução, isto permite que ele só aqueça em contato com uma panela adequada para o mesmo. Porém, enquanto a panela eletromagnética aquece por indução, o calor acumulado na própria panela é conduzido para a superfície vítrea da base do fogão, portanto o risco de queimaduras permanece. Risco eminente a este tipo de produto;

- Conforto: em termos gerais, o produto não gera desconforto ao usuário e nem possui aspectos que possam machucá-lo, a não serem as quinas visíveis. O fogão é agradável ao toque, possui um peso leve (cerca de $2 \mathrm{~kg}$ ) e não apresenta característica que possam trazer desconforto ao usuário durante o uso;

- Estereótipo popular: O manejo e utilização do produto fogem do que o usuário está acostumado com outros modelos de fogões. Além do fato do produto apresentar a tecnologia touchscreen, ele possui funções que não são autoexplicativas, como o fato do usuário ter que ajustar a potência após ligar o fogão, para que ele inicie o aquecimento;

- Envoltório de alcances físicos: O produto apresenta restrições para a maior parte dos usuários, por meio da dificuldade de percepção e compreensão das funções;

- Postura: O uso do produto não interfere na postura do usuário, já que ele não é pesado e nem exige movimentos bruscos ou arriscados;

- Aplicação da força: Nesse produto o uso da força aparece apenas em seu manuseio de um local para outro.

Para melhor conhecer o público alvo e seu entendimento e compreensão relacionados aos fogões, foram gerados painéis visuais dos usuários em potencial, que são principalmente adultos de 20 a 60 anos, de classe média/alta; deficientes visuais ou normovisuais que façam uso do fogão e busquem em seu cotidiano praticidade e autonomia ao cozinhar; podendo também atender a usuários sem restrições físicas ou cognitivas, pelo fato do produto buscar abranger o maior número de usuários possível, apresentando assim, um design universal, contudo, visando estabelecer itens relevantes como: formas, cores e temas, aos usuários e ao ambiente de contexto do produto. Posteriormente foram definidos os requisitos e parâmetros do projeto.

A partir destas análises, foi gerado um quadro de requisitos e parâmetros ergonômicos e de segurança (Quadro 2) a fim de sistematizar as diretrizes geradas com foco nos princípios do Design Universal. Ou seja, a proposta do projeto prevê que um novo produto seja desenvolvido para o uso não apenas dos deficientes visuais, mas também com possiblidade de uso por usuários normovisuais e com outra(s) deficiência(s). Os parâmetros apresentados nortearam as diretrizes das etapas posteriores do referido projeto. 
Quadro 2: Requisitos e parâmetros de projeto de um fogão por indução

\begin{tabular}{|c|c|c|c|}
\hline \multicolumn{2}{|l|}{ REQUISITOS } & PARÂMETROS & PRIORIDADE \\
\hline \multirow{6}{*}{ ERGONÔMICOS } & $\begin{array}{l}\text { Uso equitativo } \\
\text { e flexível }\end{array}$ & $\begin{array}{l}\text { O fogão deve ser utilizável por qualquer indivíduo. Seguir } \\
\text { princípio do estereótipo popular. Uso flexível para todos, } \\
\text { independentemente de habilidades. Comandos que } \\
\text { atendam destros e canhotos. }\end{array}$ & Obrigatório \\
\hline & $\begin{array}{l}\text { Simplicidade e } \\
\text { Intuição }\end{array}$ & $\begin{array}{l}\text { Baixa complexidade de uso, poucos comandos, poucas } \\
\text { sequências de tarefas, poucos botões. }\end{array}$ & Obrigatório \\
\hline & $\begin{array}{l}\text { Informação e } \\
\text { percepção }\end{array}$ & $\begin{array}{l}\text { Sistema em Braile e alto relevo integrados, que indiquem } \\
\text { funções como ligar/desligar e potência. }\end{array}$ & Obrigatório \\
\hline & $\begin{array}{l}\text { Esforço físico } \\
\text { baixo }\end{array}$ & $\begin{array}{l}\text { Acionamentos por botões de giro. Comandos onetouch } \\
\text { (touchscreen). Utilizar reconhecimento de voz } \\
\text { compatível com sistemas Android e IOS }\end{array}$ & Opcional \\
\hline & $\begin{array}{l}\text { Princípio do } \\
\text { estereótipo } \\
\text { popular }\end{array}$ & $\begin{array}{l}\text { Usar referências do repertório do usuário. Porém com } \\
\text { funções adicionais e autoexplicativas. }\end{array}$ & Obrigatório \\
\hline & Dimensional & $\begin{array}{l}\text { Medidas do fogão com base na antropometria do público } \\
\text { alvo, abrangendo todos os percentis. }\end{array}$ & Obrigatório \\
\hline \multirow{5}{*}{ SEGURANÇA } & $\begin{array}{l}\text { Sistema de } \\
\text { Aquecimento }\end{array}$ & Através de eletromagnetismo (fogão por indução) & Obrigatório \\
\hline & $\begin{array}{l}\text { Tolerância ao } \\
\text { erro }\end{array}$ & $\begin{array}{l}\text { Minimizar riscos de acidente através de sistema de } \\
\text { desligamento de fácil acesso e desligamento automático } \\
\text { em falhas e superaquecimento. }\end{array}$ & Opcional \\
\hline & $\begin{array}{l}\text { Emissão de } \\
\text { sinais sonoros }\end{array}$ & $\begin{array}{l}\text { Através de uma pequena saída de som estéreo acoplada } \\
\text { ao fogão }\end{array}$ & Opcional \\
\hline & $\begin{array}{l}\text { Encaixe da } \\
\text { panela }\end{array}$ & $\begin{array}{l}\text { Delimitação da área correta de encaixe com sinalizadores } \\
\text { fixos ao redor da área central da panela }\end{array}$ & Obrigatório \\
\hline & Botão tátil & $\begin{array}{l}\text { Emitir avisos/notificações através de um feedback } \\
\text { sonoro }\end{array}$ & Obrigatório \\
\hline \multirow{2}{*}{ MERCADOLÓICO } & $\begin{array}{l}\text { Preço médio/ } \\
\text { alto }\end{array}$ & Valor estimado entre 300 e 600 reais & Opcional \\
\hline & Classe social & Adultos de 20 a 60 anos, de classe média/alta & Opcional \\
\hline \multirow[t]{2}{*}{ ESTÉTICO - FORMAL } & $\begin{array}{l}\text { Forma } \\
\text { geométrica } \\
\text { com partes } \\
\text { orgânicas }\end{array}$ & $\begin{array}{l}\text { Deverá apresentar uma forma possivelmente retangular, } \\
\text { com quinas e botões boleados. }\end{array}$ & Obrigatório \\
\hline & $\begin{array}{l}\text { Cores quentes } \\
\text { e } \\
\text { contrastantes }\end{array}$ & Utilizar o amarelo, branco e/ou tons amadeirados. & Opcional \\
\hline \multirow[t]{2}{*}{ MATERIAL } & Leve & $\begin{array}{l}\text { Baixo peso, para que seja possível de ser transportado } \\
\text { pelo consumidor. }\end{array}$ & Opcional \\
\hline & Proteção & Capa protetora resistente a pequenos impactos. & Opcional \\
\hline
\end{tabular}

Fonte: Os autores (2017). 


\section{Considerações Finais}

Ao concluir essa pesquisa, pôde-se perceber que foi realizado um exercício para melhor compreensão do universo dos deficientes visuais, mesmo que preliminarmente, onde a partir daí, houve a possibilidade da captação de informações sobre as características presentes no produto a ser projetado futuramente, como também do público que irá fazer uso dele. Essas análises e reflexões das características e peculiaridades do público alvo possibilitam a criação de produtos pensados para atender as mais diversas singularidades.

A manutenção da autonomia e da independência do deficiente visual são premissas importantes para todos os indivíduos, assim como, para as políticas sociais. Cabe, portanto, a toda sociedade, projetistas, fabricantes, dentre outros stakehoders, prover meios, produtos e ambientes, seguros a este público, com intuito de alcançar a inclusão social, que lhes é de direito. Neste sentido, diversos autores enfatizam a importância do papel do designer no desenvolvimento dos produtos. Assim como a adoção dos princípios do DU que, segundo Duncan (2013) demonstra ser uma abordagem com potencial para melhorar a acessibilidade e usabilidade de produtos e ambientes, além dos requisitos mínimos impostos pela lei.

Verificou-se por meio do uso da metodologia GODP (MERINO, 2016), que o projeto centrado no usuário nos permite colocar o usuário no foco das etapas de desenvolvimento de produtos para diferentes públicos, e neste caso, para deficientes visuais. Desta forma, foram percorridas as etapas iniciais do projeto de levantamento e organização de dados, tomando os devidos cuidados com a interação do produto com as características e experiências do usuário em potencial. Os desafios estavam não somente em reunir os usuários e levantar informações necessárias, mas analisá-las, organizá-las e convertê-las em um quadro de requisitos e parâmetros na forma de diretrizes para solução da problemática apresentada. Com a conclusão destas etapas, pode-se dar prosseguimento ao desenvolvimento do produto proposto por meio do cumprimento das etapas projetuais do método nas fases seguintes, quais sejam: criação, execução e validação. Tem-se a clareza que, o ideal para a condução dos testes seria incluir o usuário real no processo. Contudo, mesmo não tendo sido possível, entende-se que, a experiência foi produtiva quanto ao processo de aprendizagem e exercício projetual, bem como a operacionalização das etapas e ferramentas utilizadas.

\section{REFERÊNCIAS}

BERSCH, R., 2013. Introdução à Tecnologia Assistiva. Disponível em <http://www.assistiva.com.br/Introducao_Tecnologia_Assistiva.pdf> Acesso em: 15 jun. 2017.

CUD. CENTER FOR UNIVERSAL DESIGN. Universal Design Principles. Disponível em: https://www.ncsu.edu/ncsu/design/cud/about_ud/udprinciples.htm>. Acesso em: 15 jun. 2017.

DIAS DE SÁ, E. MARIA DE CAMPOS, I. CAMPOLINA SILVA, M. B. Atendimento Educacional Especializado: Deficiência Visual. Brasília: Cromos. Brasília/DF, 2007.

DUNCAN, Richard. Universal Design for the 21st century iris hamp international perspectives. Disponível em: http://www.universaldesign.ie/exploreampdiscover/conference proceedings/universaldesignforthe21stcenturyirishampinternationalperspectives/universaldesign Universal Design. 
GOUVÊA LÁZARO, R. C. MAIA, H. Inclusão do Aluno com Baixa Visão na Rede Regular de Ensino: a que Custo?. Rio de Janeiro. Acesso em: 15 jun. 2017.

IIDA, Itiro. Ergonomia: Projeto e Produção. 2. ed. Rio de Janeiro: Edgard Blücher, 2005.

MANZINI, E. J. Tecnologia assistiva para educação: recursos pedagógicos adaptados. In: Ensaios pedagógicos: construindo escolas inclusivas. Brasília: SEESP/MEC, p. 82-86, 2005.

MERINO, Giselle Schmidt Alves Díaz. GODP Projetos: Uma metodologia de Design Centrado no Usuário. Florianópolis: Ngd/ Ufsc, 2016. Disponível em: (www.ngd.ufsc.br). Acesso em: 12 jul. 2016.

MERINO, Giselle Schmidt Alves Díaz. Metodologia para a prática projetual do Design com base no Projeto centrado no Usuário e com ênfase no Design Universal. 2014. 212 f. Tese (Doutorado) Curso de Programa de Pós-graduação em Engenharia de Produção, Departamento de Engenharia de Produção e Sistemas, Universidade Federal de Santa Catarina, Florianópolis, 2014. Disponível em: 〈http://tede.ufsc.br/teses/PEPS5573-T. pdf〉. Acesso em: 20 jun. 2018.

MICHEL, Bruna Magda; CEZAR, Marina Seibert. A Cultura e sua relevância na criação de produtos de consumo. In: II Conferência Internacional de Design, Engenharia e Gestão para a inovação. Anais. Florianópolis, SC. 2012.

MIRANDA, M. J. C. Inclusão Escolar e Deficiência Visual: Trajetória e Processo. Maringá: 2001. Disponível em: < http://seer.fclar.unesp.br/iberoamericana/article/viewFile/2678/2388> Acesso em: 15 jun. 2017.

VENTAVOLI, F. M. A. A informática como ferramenta e proposta educativa aos indivíduos portadores de Deficiência Visual. Edição do autor. Mococa, p. 36-39, 2012. Disponível em: < http://www.dominiopublico.gov.br/download/texto/ea001023.pdf> Acesso em: 15 jun. 2017. 